\title{
LA ACREDITACIÓN DE LAS CARRERAS ARTÍSTICAS DE PREGRADO EN CHILE
}

\section{Introducción}

El presente artículo tiene como objetivo dar a conocer el actual escenario en el que se desarrollan los procesos de acreditación de carreras universitarias de arte en Chile, sobre la base de la Ley $\mathrm{N}^{\circ} 20.129$, con especial énfasis en las agencias acreditadoras. El artículo se basa en los resultados de una investigación realizada (20121013) acerca de los datos que exhiben las agencias de acreditación especializadas en artes y los programas universitarios de pregrado solo en esta área. En el estudio se han considerado, por lo tanto, solo las disciplinas de música, teatro, artes visuales, cine, danza, estética, teoría e historia del arte; y a las cuatro agencias acreditadoras focalizadas en ellas. En otras palabras, el documento está referido solo a las carreras cuyos alumnos hacen obras (de arte) y/o la analizan desde una perspectiva histórica o filosófica.

El texto expone además las acciones que en su momento emprendió el Consejo Nacional de la Cultura y las Artes (CNCA) en el tema y las experiencias acerca de la materia acumuladas en cinco países de América Latina.

\section{Las agencias chilenas de acreditación en el área de las artes y los pares evaluadores}

La Ley $\mathrm{N}^{\circ} 20.129^{3}$ promulgada el 23 de octubre de 2006, en sus párrafos $2^{\circ}$ y $3^{\circ}$, regula el funcionamiento de las agencias acreditadoras en las que el Estado de Chile ha delegado la aplicación de algunos procesos de acreditación. Hoy son cuatro las agencias especializadas en las distintas disciplinas del arte, que operan en el sistema nacional:

Para mayor información se puede consultar el siguiente enlace: http://www.leychile.cl/ Navegar?idNorma $=255323$. 
a. Qualitas (2008) (www.qualitas.cl) atiende a todas las carreras profesionales, técnicas y programas de pregrado de administración y comercio, arte, ciencias sociales, humanidades, recursos humanos y tecnología, siempre que no sean impartidas por la Pontificia Universidad Católica o sus filiales. En 2010 extiende su área de acreditación a ciencias, derecho (técnico superior), ciencias agropecuarias, ciencias sociales, educación y tecnologías en nivel de magíster. El consejo de acreditación del área artística está integrado por siete personas, de las cuales cuatro son licenciados/titulados (teórico del arte, músico, bailarina y arquitecto), dos magíster (historiador del arte y actor) y un doctor (músico). Trabajan en la Universidad de Chile, Universidad Academia de Humanismo Cristiano, Universidad Diego Portales, DUOC, Universidad Andrés Bello y dos de ellos en la Pontificia Universidad Católica de Chile. Así mismo, el consejo declara tener 34 pares evaluadores para el área, quienes en su mayoría estudiaron en la Universidad de Chile y en el extranjero.

Gráfico 1: Grado académico de los pares evaluadores de la agencia Qualitas

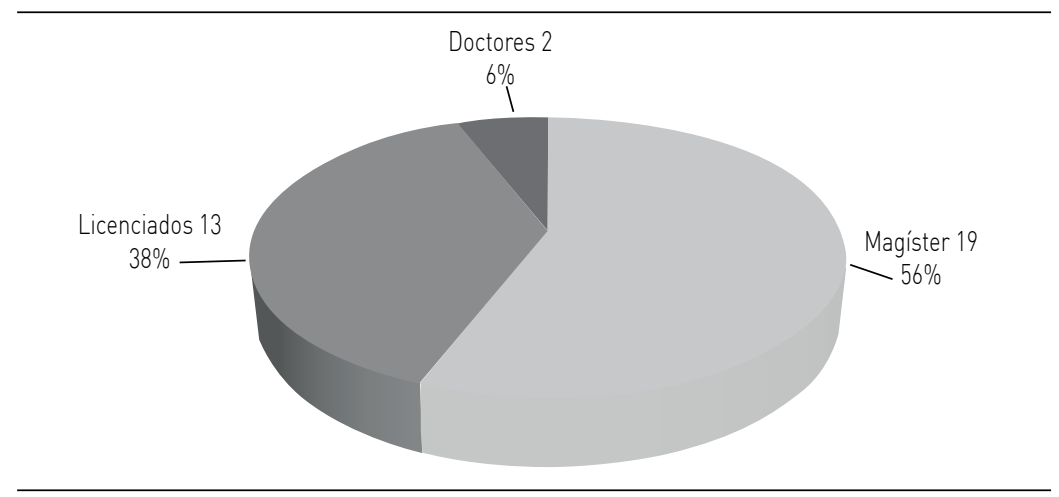

Fuente: Qualitas (2014). 
132 LA ACREDITACIÓN DE LAS CARRERAS ARTÍSTICAS DE PREGRADO EN CHILE I. Villegas

Tabla 1: Origen de los estudios y actuales empleadores de pares evaluadores

\begin{tabular}{l|c|c|l|c|c}
\hline \multicolumn{1}{c|}{ Estudiaron en } & $N^{0}$ & $\%$ & \multicolumn{1}{|c|}{ Actuales empleadores } & $N^{0}$ & $\%$ \\
\hline U. A. Ibáñez & 1 & 3 & U. Academia Humanismo Cristiano & 1 & 3 \\
\hline U. ARCIS & 1 & 3 & U. Alberto Hurtado & 1 & 3 \\
\hline U. Católica & 3 & 9 & U. ARCIS & 2 & 6 \\
\hline U. Católica de Valparaíso & 2 & 6 & U. Austral & 1 & 3 \\
\hline U. de Chile & 7 & 21 & U. Autónoma de Chile & 1 & 3 \\
\hline U. de Concepción & 1 & 3 & U. Católica & 8 & 23 \\
\hline U. del Desarrollo & 1 & 3 & U. Católica de Valparaíso & 2 & 3 \\
\hline U. Diego Portales & 1 & 3 & U. de Chile & 5 & 14,7 \\
\hline U. de Talca & 1 & 3 & U. de Concepción & 2 & 6 \\
\hline Universidades extranjeras & 14 & 41 & U. Diego Portales & 2 & 6 \\
\hline No hay datos & 2 & 6 & DUOC & 4 & 11,8 \\
\hline & & & Liceo Experimental Artístico & 1 & 3 \\
\hline & & & U. Mayor & 1 & 3 \\
\hline & & & U. de Santiago & 1 & 3 \\
\hline TOTAL & & & U. de Valparaíso & 2 & 6 \\
\hline
\end{tabular}

Fuente: Qualitas (2014).

b. AAD S.A. (2008) (www.aadsa.cl) atiende a las áreas de arquitectura, diseño y artes visuales, en niveles técnico, profesional (pregrado) y maestrías. Posee un directorio integrado por seis personas: un gestor cultural (magíster), un artista visual (licenciado) y cuatro arquitectos (uno de ellos doctor) y un consejo de acreditación de carreras de pregrado integrado por cinco personas (tres arquitectos y dos diseñadores: todos licenciados, salvo un magíster), estos académicos trabajan en la Universidad de Talca, Pontificia Universidad Católica, Pontificia Universidad Católica de Valparaíso (2), Universidad de Chile. Declara tener 16 pares evaluadores para el área del arte, quienes en su mayoría estudiaron en la Universidad de Chile. No hay evaluadores de provincia. 
Gráfico 2: Grado académico de los pares evaluadores de la agencia AAD SA

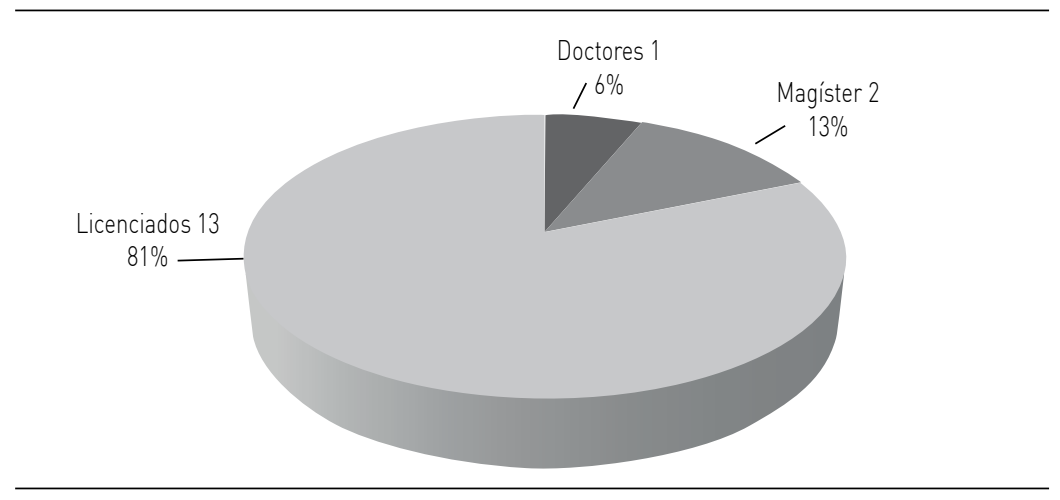

Fuente: AADSA (2014).

Tabla 2: Origen de los estudios y actuales empleadores de pares evaluadores agencia AAD S.A.

\begin{tabular}{l|c|c|l|c|c}
\hline \multicolumn{1}{c|}{ Estudiaron en } & $N^{0}$ & $\%$ & \multicolumn{1}{|c|}{ Actuales empleadores } & $N^{0}$ & $\%$ \\
\hline U. Católica & 3 & 19 & U. Católica & 1 & 6 \\
\hline U. de Chile & 11 & 69 & U. de Chile & 13 & 81 \\
\hline Universidades extranjeras & 2 & 13 & Universidades extranjeras & 1 & 6 \\
\hline & & & U. Finis Terrae & 1 & 6 \\
\hline TOTAL & 16 & $100 \%$ & & 16 & $100 \%$ \\
\hline
\end{tabular}

Fuente: AADSA (2014).

c. Agencia Acreditadora de Chile (2009) (A\&C) (www. acreditadoradechile.cl) para las áreas de administración y comercio, arte y arquitectura, ciencias, derecho, educación, humanidades, recursos naturales, salud (medicina a partir de 2014) y tecnología. Su consejo de acreditación para el área de arte está integrado por ocho personas: un doctor en historia del arte y un doctor en comunicaciones, un artista visual sin grado, un artista visual licenciado, un arquitecto y una diseñadora, un magíster en arquitectura, un actor con grado de magíster. Todos ellos trabajan en la Universidad de Talca, Universidad del Desarrollo, UNIACC, Universidad Diego Portales, Universidad Finis Terrae, DUOC y dos en la empresa privada. Declara un registro de 82 evaluadores en el área de arte. 
134 LA ACREDITACIÓN DE LAS CARRERAS ARTÍSTICAS DE PREGRADO EN CHILE I. Villegas

Gráfico 3: Grado académico de los pares evaluadores de la agencia A\&C

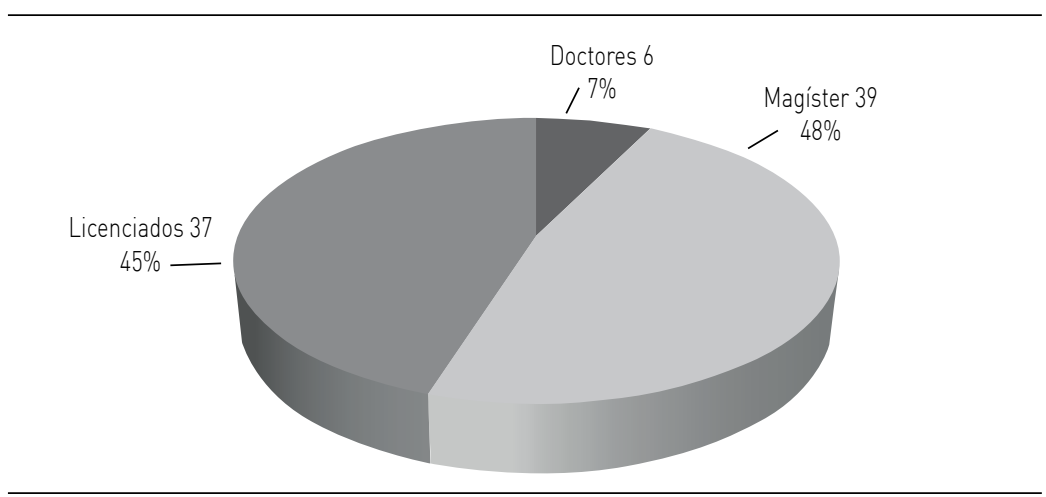

Fuente: Agencia Acreditadora de Chile (2014).

Tabla 3: Origen de los estudios y actuales empleadores Agencia Acreditadora de Chile $(A \& C)$

\begin{tabular}{l|c|c|l|c|c}
\hline \multicolumn{1}{c|}{ Estudiaron en } & $N^{0}$ & $\%$ & \multicolumn{1}{|c|}{ Actuales empleadores } & $N^{0}$ & $\%$ \\
\hline U. A. Ibáñez & 1 & 1,2 & U. Andrés Bello (Viña del Mar) & 1 & 1,2 \\
\hline U. Andrés Bello & 1 & 1,2 & U. Andrés Bello (Santiago) & 1 & 1,2 \\
\hline U. ARCIS & 1 & 1,2 & Academia Projazz & 1 & 1,2 \\
\hline U. del Bío Bío & 4 & 4,9 & U. A. Ibáñez & 1 & 1,2 \\
\hline U. Católica & 8 & 9,8 & AlEP & 1 & 1,2 \\
\hline U. Católica de Valparaíso & 1 & 1,2 & U. ARCIS & 1 & 1,2 \\
\hline U. de Chile & 21 & 25,6 & U. Austral & 2 & 2,4 \\
\hline U. del Mar & 1 & 1,2 & U. Autónoma de Chile & 1 & 1,2 \\
\hline U. del Desarrollo & 2 & 2,4 & U. Católica & 5 & 6,1 \\
\hline U. Diego Portales & 3 & 3,7 & U. Católica de Valparaíso & 2 & 2,4 \\
\hline U. Finis Terrae & 1 & 1,2 & U. de Chile & 9 & 11 \\
\hline IEDE & 1 & 1,2 & U. de Concepción & 2 & 2,4 \\
\hline INACAP & 1 & 1,2 & U. del Desarrollo & 6 & 7,3 \\
\hline Instituto Profesional de Santiago & 1 & 1,2 & U. Diego Portales & 2 & 2,4 \\
\hline Instituto Mónica Herrera & 1 & 1,2 & DUOC & 5 & 6,1 \\
\hline U. de La Serena & 1 & 1,2 & Escuela Moderna Música & 1 & 1,2 \\
\hline U. de Santiago & 1 & 1,2 & U. Finis Terrae & 3 & 3,7 \\
\hline U. T. F. Santa María & 1 & 1,2 & INACAP & 4 & 4,9 \\
\hline UNIACC & 1 & 1,2 & U. de La Serena & 2 & 2,4 \\
\hline Universidades extranjeras & 21 & 25,6 & U. Mayor & 4 & 4,9 \\
\hline UMCE & 4 & 4,9 & UMCE & 5 & 6,1 \\
\hline U. del Pacífico & 2 & 2,4 & U. del Pacífico & 1 & 1,2 \\
\hline U. de Playa Ancha & 2 & 2,4 & U. de Playa Ancha & 1 & 1,2 \\
\hline U. de Talca & 1 & 1,2 & U. San Sebastián & 1 & 1,2 \\
\hline & & & UNIACC & 2 & 2,4 \\
\hline & & & $c 0 n$ \\
\hline
\end{tabular}


continuación Tabla 3

\begin{tabular}{l|c|c|l|c|c}
\hline Estudiaron en & $\mathrm{N}^{0}$ & $\%$ & \multicolumn{1}{|c|}{ Actuales empleadores } & $\mathrm{N}^{0}$ & $\%$ \\
\hline & & & U. de Talca & 1 & 1,2 \\
\hline & & & UTEM & 1 & 1,2 \\
\hline & & & U. T. F. Santa María & 2 & 2,4 \\
\hline & & & U. de Valparaíso & 1 & 1,2 \\
\hline & & & U. Viña del Mar & 1 & 1,2 \\
\hline & & & Empresa privada & 11 & 13,4 \\
\hline & 82 & $100 \%$ & & 1 & 1,2 \\
\hline TOTAL & & & 82 & $100 \%$ \\
\hline
\end{tabular}

Fuente: Agencia Acreditadora de Chile (2014).

d. Agencia Aespigar (2012) (www.aespigar.cl). Acredita carreras del área de artes y diseño, administración y comercio, ciencias sociales y educación. Su consejo de acreditación para arte y arquitectura está conformado por nueve personas, cinco de la Universidad de Chile, uno de la Universidad Católica, uno de la Universidad del Bío Bío, una persona de la Universidad Finis Terrae y una persona sin filiación universitaria. Dos son doctores, cinco magíster y dos son licenciados. Tres son arquitectos, un artista visual, un dramaturgo, un teórico del arte, un músico, un diseñador y un profesor de artes plásticas. Declara contar con 141 pares evaluadores disponibles.

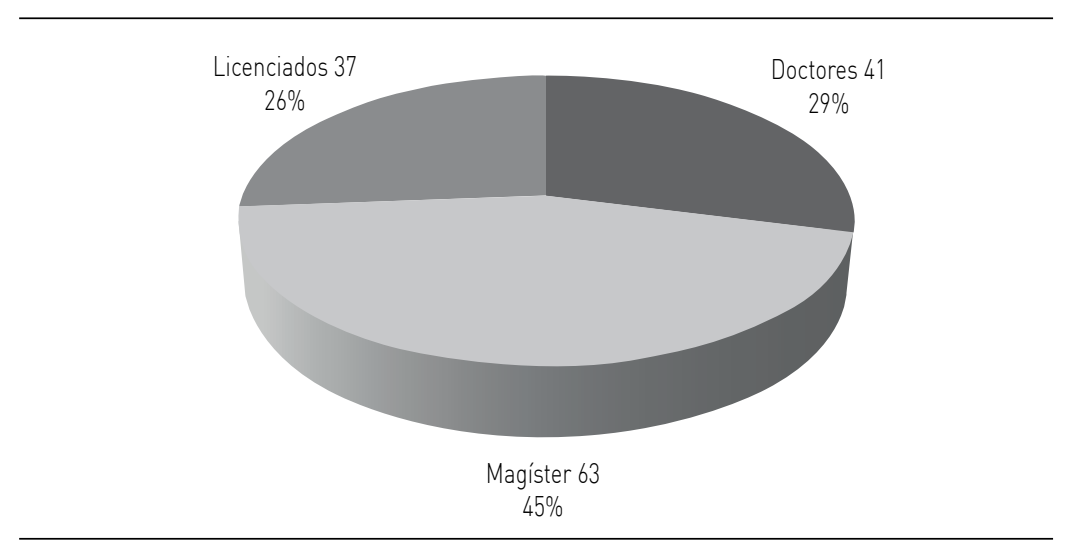

Gráfico 4: Grado académico de los pares evaluadores de la agencia Aespigar 
136 LA ACREDITACIÓN DE LAS CARRERAS ARTÍSTICAS DE PREGRADO EN CHILE I. Villegas

Tabla 4: Origen de los estudios y actuales empleadores de la agencia Aespigar

\begin{tabular}{|c|c|c|c|c|c|}
\hline Estudiaron en & $\mathrm{N}^{0}$ & $\%$ & Actuales empleadores & $\mathrm{N}^{0}$ & $\%$ \\
\hline U. Academia Humanismo Cristiano & 4 & 2,8 & U. Academia Humanismo Cristiano & 10 & 7,1 \\
\hline U. A. Ibáñez & 1 & 0,7 & U. A. Ibáñez & 2 & 1,4 \\
\hline U. Alberto Hurtado & 1 & 0,7 & U. Alberto Hurtado & 1 & 0,7 \\
\hline U. de Antofagasta & 1 & 0,7 & U. Andrés Bello (Santiago) & 2 & 1,4 \\
\hline U. ARCIS & 3 & 2,1 & U. de Antofagasta & 3 & 2,1 \\
\hline U. del Bío Bío & 1 & 0,7 & U. ARCIS & 5 & 3,5 \\
\hline U. Católica de Chile & 12 & 8,5 & U. A. Prat & 1 & 0,7 \\
\hline U. Católica de Valparaíso & 1 & 0,7 & U. del Bío Bío & 1 & 0,7 \\
\hline U. de Chile & 37 & 26,2 & U. Bolivariana & 1 & 0,7 \\
\hline U. de Concepción & 1 & 0,7 & U. Católica de Chile & 5 & 3,5 \\
\hline U. Central & 2 & 1,4 & U. Católica del Norte & 2 & 1,4 \\
\hline U. Diego Portales & 1 & 0,7 & U. Central & 8 & 5,7 \\
\hline EDUCARES & 1 & 0,7 & U. Chile & 20 & 14,2 \\
\hline INACAP & 1 & 0,7 & UCINF & 1 & 0,7 \\
\hline IPV & 1 & 0,7 & CIDEM & 1 & 0,7 \\
\hline U. de La Frontera & 1 & 0,7 & U. del Desarrollo (Concepción) & 1 & 0,7 \\
\hline U. de La República & 1 & 0,7 & U. del Desarrollo (Santiago) & 3 & 2,1 \\
\hline U. de La Serena & 1 & 0,7 & U. del Mar & 3 & 2,1 \\
\hline U. Mayor & 2 & 1,4 & U. Diego Portales & 4 & 2,8 \\
\hline U. de Santiago & 6 & 4,3 & DUOC & 1 & 0,7 \\
\hline UMCE & 3 & 2,1 & U. Iberoamericana & 2 & 1,4 \\
\hline Universidades extranjeras & 54 & 38,3 & U. Internacional SEK & 5 & 3,5 \\
\hline U. de Playa Ancha & 2 & 1,4 & Instituto Profesional Providencia & 1 & 0,7 \\
\hline U. de Tarapacá & 1 & 0,7 & Instituto Carlos Casanueva & 1 & 0,7 \\
\hline \multirow[t]{17}{*}{ U. Tecnológica Metropolitana } & 2 & 1,4 & U. de La Serena & 2 & 1,4 \\
\hline & & & U. de Los Lagos & 4 & 2,8 \\
\hline & & & U. Miguel de Cervantes & 3 & 2,1 \\
\hline & & & UMCE & 12 & 8,5 \\
\hline & & & U. del Pacífico & 2 & 1,4 \\
\hline & & & U. de Playa Ancha & 4 & 2,8 \\
\hline & & & U. Santísima Concepción & 1 & 0,7 \\
\hline & & & U. de Santiago & 5 & 3,5 \\
\hline & & & U. del Cardenal Raúl Silva Henríquez & 1 & 0,7 \\
\hline & & & U. de Talca & 1 & 0,7 \\
\hline & & & UTEM & 2 & 1,4 \\
\hline & & & Teatro Sombra & 1 & 0,7 \\
\hline & & & U. de Valparaíso & 4 & 2,8 \\
\hline & & & Empresa privada & 1 & 0,7 \\
\hline & & & Empresa pública & 3 & 2,1 \\
\hline & & & Universidades extranjeras & 1 & 0,7 \\
\hline & & & No trabaja & 10 & 7,1 \\
\hline TOTAL & 141 & $100 \%$ & Total & 141 & $100 \%$ \\
\hline
\end{tabular}

Fuente: Aespigar (2012). 
A lo anterior debemos agregar a la Comisión Nacional de Acreditación (CNA), la que declara tener 55 evaluadores para el área de arte, pero solo atiende a posgrado.

Las agencias especializadas en acreditar carreras del área artística son instituciones que no tienen más antigüedad que el sistema mismo. Del total de 273 pares evaluadores, 100 tienen el grado de licenciado (36,6\%); 127 el de magíster (45,1\%) y 47 el de doctor (18,3\%), es decir, el 63,4\% de los pares evaluadores del sistema poseen estudios de posgrado. Es importante precisar que las agencias no obligan a que sus evaluadores ni integrantes de comités de acreditación posean un posgrado.

Por otro lado, en relación con la información que las agencias hacen circular hay que señalar que esta no permite la comparación entre una y otra. Por ejemplo, no queda claro si todas tienen planes de perfeccionamiento para sus pares evaluadores; tampoco se observan vínculos entre sí o con otras agencias a fin de medir o poner a prueba sus propios sistemas de evaluación de la calidad del desempeño de los programas. También es preciso señalar que las agencias han comenzado a ejercer su labor en el extranjero.

La ley no especifica si los consejos de área deben o no estar integrados por personas activas en el mundo de la academia. No existe en los párrafos 2 y 3 (entre los Artículos No 34 y No 43) ninguna cláusula que especifique la forma en que se comprueba la idoneidad de los recursos humanos de una agencia acreditadora.

Las cuatro agencias de acreditación exhiben entre los integrantes de los comités de acreditación a representantes de las más variadas actividades del arte: bailarinas, músicos, artistas visuales, dramaturgos, historiadores del arte, arquitectos, diseñadores. Cabe señalar que el consejo de acreditación (para artes) de la agencia AAD S.A. está integrado solo por arquitectos y diseñadores.

Respecto de los pares evaluadores la ley solo indica que deben "ser reconocidos en su área de especialidad"4. El reconocimiento de

\footnotetext{
4 Ver Artículo No 19, Título 2 de la ley.
} 
una persona en cualquier especialidad de las artes es de suyo un problema cultural y no un asunto de currículum, en torno al cual no existen acuerdos claros y tácitos. Las universidades ya poseen esta dificultad a la hora de otorgar categorías académicas y evaluaciones/ calificaciones a los docentes del área artística ${ }^{5}$.

No existe en Chile un mecanismo que permita comparar dos acreditaciones en dos programas diferentes y en lugares distintos del país. En otras palabras, cada agencia mide poniendo énfasis en los aspectos que le parecen necesarios y pertinentes, siendo sus evaluadores quienes deciden y sus consejos de área quienes sancionan.

\section{Los programas universitarios en artes}

En relación con los procesos de acreditación de pregrado en $\operatorname{artes}^{6}$, podemos señalar que hasta 2013 existían en Chile 52 programas de arte de nivel universitario y de ellos solo diez habían obtenido acreditación $(19 \%)^{7}$. El carácter voluntario que tiene el incorporarse a un sistema de aseguramiento de la calidad, basado en informes, autoevaluación y evaluaciones por pares externos, agrega una cuota importante de trabajo a las carreras de artes, lo que demanda a su vez una estructura académico-administrativa sólida y experta que, al parecer, no se ha implementado de manera masiva. En efecto, la investigación que realizamos en 2012-2013 detectó que los programas de arte del sistema universitario nacional, dirigidos casi siempre por artistas, no cuentan en sus equipos directivos con autoridades ni personal que provengan del área de la administración, o profesionales y administrativos con conocimientos de evaluación, metodologías cualitativas y/o sistemas. De la misma forma, estos programas no reportan la existencia de un equipo propio, que regule y sistematice

5 Ver por ejemplo el documento "Políticas de gestión del cuerpo docente" en http://www7. uc.cl/dadevra/wseleccion/PDFs/politicasAcademicas.pdf. Se trata de un documento de 2008 que fija normas que permitirían medir el buen desempeño de sus académicos, entendido como un nivel de reconocimiento. En la Pontificia Universidad Católica se delega la observación del "buen desempeño" de sus académicos a una comisión especializada en cada disciplina, que cada dos años analiza el currículum de cada académico.

6 Recordamos al lector que nos estamos refiriendo a carreras con un claro contenido centrado en creación y/o reflexión respecto de obras de arte.

Algunos programas ya están próximos a iniciar su etapa de reacreditación. 
todos los aspectos del aseguramiento de la calidad académica que ofrecen. Solo el programa de Licenciatura en arte de la Universidad de Concepción declara tener un docente con grado de MBA en evaluación de proyectos y el programa de Licenciatura en Arte UC reportó tener (hasta 2013) una oficina de aseguramiento de la calidad.

El claustro académico estable de los programas de arte que ofrecieron matrícula durante el año 2012 se componía de 950 docentes. De estos (para aquellos que informan respecto del grado académico de sus profesores) 83 poseen el grado de doctor (9\%); 122 el de magíster, master o DEA (14\%); 438 solo la licenciatura (51\%), 158 (18\%) declaran poseer otros títulos, o bien, no tener ninguno. El adiestramiento en procesos de evaluación de currículo, que comprende el dominio de metodologías cualitativas y cuantitativas no queda asegurado plenamente, salvo por los doctores y las acciones que organizan las agencias.

Del análisis de las mallas curriculares se puede inferir que un componente que diferencia a estos programas de pregrado de otros en disciplinas distintas como las ciencias sociales o ciencias básicas, es la existencia de talleres de producción de obras y otros (talleres o seminarios) de análisis de obras, ambos de corte subjetivo, con pocas vacantes, en general con más de una sección. Estos cursos ofrecen la posibilidad de orientar el trabajo del estudiante hacia caminos, visiones o tendencias particulares. En teatro, una formación centrada en la comedia del arte será manifiestamente distinta en términos de su metodología de una formación centrada en la noción de teatro del gesto. Por su parte la composición musical contemporánea entiende de distinta manera una obra, en tanto esta sea elaborada por las nuevas tecnologías de audio, o bien, por instrumentos de cuerdas tradicionales. Dichas posturas generarán "maneras de hacer", cuando no verdaderos sesgos en el proceso de enseñanza y aprendizaje. Tanto los procesos de autoevaluación como la evaluación de pares y la discusión de los consejos de acreditación debieran observar atentamente estos rasgos.

Se excluye de los posgrados a la maîtrise (francesa), por corresponder a la última etapa de estudios de pregrado, existente en Francia antes de la Convención de Bolonia. 
Por otra parte, el tratamiento evaluativo de contenidos y metodologías de un programa de licenciatura en el ámbito de las artes debe ser particularmente diferenciado según el sesgo cultural al que se aluda. En efecto, esta diferenciación cultural resulta relevante para los procesos de acreditación en zonas geográficas distintas del centro geográfico (y cultural) del país. El arte, por ser un asunto cultural, ofrece cambios en los contenidos de sus materias, según se trate de una cultura u otra. De esta forma, así como no es lo mismo estudiar arte en el extranjero que en Chile, no resulta igual estudiar arte en Valparaíso que en Temuco.

Tabla 5: Programas en artes existentes en Chile $\left.{ }^{*}\right)$

\begin{tabular}{c|l|l|l}
\hline \multicolumn{1}{c|}{ Disciplina } & \multicolumn{1}{|c|}{ Nombre carrera } & \multicolumn{1}{c}{ Universidad } & \multicolumn{1}{c}{ Acreditada } \\
\hline Artes visuales & Arte y Cultura Visual & U. ARCIS & \\
\hline Artes visuales & $\begin{array}{l}\text { Licenciatura en Artes } \\
\text { Visuales }\end{array}$ & U. Austral & $\begin{array}{l}2017 \\
\text { Agencia Acreditadora de } \\
\text { Chile }\end{array}$ \\
\hline Artes visuales & $\begin{array}{l}\text { Licenciatura en Artes } \\
\text { Visuales }\end{array}$ & U. de Chile & \\
\hline Artes visuales & $\begin{array}{l}\text { Licenciatura en Artes } \\
\text { Visuales }\end{array}$ & U. de Concepción & \\
\hline Artes visuales & $\begin{array}{l}\text { Licenciatura en Artes } \\
\text { Visuales }\end{array}$ & U. Católica de Temuco & \\
\hline Artes visuales & $\begin{array}{l}\text { Licenciatura en Artes } \\
\text { Visuales }\end{array}$ & U. Católica de Valparaíso & \\
\hline Artes visuales & $\begin{array}{l}\text { Licenciatura en Arte y } \\
\text { Cultura Contemporánea }\end{array}$ & U. del Desarrollo & \\
\hline Artes visuales & Licenciatura en Arte & U. Católica de Chile & $\begin{array}{l}2017 \\
\text { Agencia AADSA }\end{array}$ \\
\hline Artes visuales & Licenciatura en Arte & U. Diego Portales & \\
\hline Artes visuales & Licenciatura en Arte & U. Finis Terrae & $\begin{array}{l}2018 \\
\text { Agencia Qualitas }\end{array}$ \\
\hline Artes visuales & Licenciatura en Arte & U. Nacional Andrés Bello & \\
\hline Artes visuales & Licenciatura en Arte & UNIACC & $\begin{array}{l}2015 \\
\text { Agencia A\&C }\end{array}$ \\
\hline Estética y teoría & Licenciatura en Estética & U. Católica de Chile & $\begin{array}{l}2018 \\
\text { Agencia Acreditadora de } \\
\text { Chile }\end{array}$ \\
\hline Estética y teoría & $\begin{array}{l}\text { Licenciatura en Teoría e } \\
\text { Historia del Arte }\end{array}$ & U. Alberto Hurtado & \\
\hline & Historia del Arte & U. de Chile & \\
\hline
\end{tabular}




\begin{tabular}{|c|c|c|c|}
\hline Disciplina & Nombre carrera & Universidad & Acreditada \\
\hline Literatura & $\begin{array}{l}\text { Licenciatura Literatura } \\
\text { Creativa }\end{array}$ & U. Diego Portales & \\
\hline Literatura & Literatura & U. Finis Terrae & \\
\hline Literatura & Licenciatura en Letras & $\begin{array}{l}\text { Universidad Nacional } \\
\text { Andrés Bello }\end{array}$ & \\
\hline Literatura & Licenciatura en Letras & U. Católica de Chile & $\begin{array}{l}2018 \\
\text { Agencia Acreditadora de } \\
\text { Chile }\end{array}$ \\
\hline $\begin{array}{l}\text { Comunicación } \\
\text { audiovisual }\end{array}$ & Comunicación Audiovisual & U. Católica de Chile & \\
\hline $\begin{array}{l}\text { Comunicación } \\
\text { audiovisual }\end{array}$ & $\begin{array}{l}\text { Comunicación } \\
\text { Audiovisual/Cine }\end{array}$ & UNIACC & \\
\hline $\begin{array}{l}\text { Comunicación } \\
\text { audiovisual }\end{array}$ & $\begin{array}{l}\text { Comunicación Audiovisual } \\
\text { y Multimedia }\end{array}$ & U. de las Américas & \\
\hline $\begin{array}{l}\text { Comunicación } \\
\text { audiovisual }\end{array}$ & $\begin{array}{l}\text { Cine y Comunicación } \\
\text { Audiovisual }\end{array}$ & U. Viña del Mar & \\
\hline $\begin{array}{l}\text { Comunicación } \\
\text { audiovisual }\end{array}$ & Cine & U. ARCIS & \\
\hline $\begin{array}{l}\text { Comunicación } \\
\text { audiovisual }\end{array}$ & Cine & U. del Desarrollo & \\
\hline $\begin{array}{l}\text { Comunicación } \\
\text { audiovisual }\end{array}$ & Animación y Arte Digital & U. de las Américas & \\
\hline $\begin{array}{l}\text { Comunicación } \\
\text { audiovisual }\end{array}$ & Animación Digital & U. G. Mistral & \\
\hline $\begin{array}{l}\text { Comunicación } \\
\text { audiovisual }\end{array}$ & Animación Digital & U Mayor & \\
\hline $\begin{array}{l}\text { Comunicación } \\
\text { audiovisual }\end{array}$ & Cine & U. Mayor & \\
\hline $\begin{array}{l}\text { Comunicación } \\
\text { audiovisual }\end{array}$ & $\begin{array}{l}\text { Comunicación y } \\
\text { Animación Digital }\end{array}$ & UNIACC & \\
\hline $\begin{array}{l}\text { Comunicación } \\
\text { audiovisual }\end{array}$ & Cine & U. de Valparaíso & \\
\hline Música & $\begin{array}{l}\text { Licenciatura Arte } \\
\text { Tecnología y Gestión } \\
\text { Musical }\end{array}$ & U. de Valparaíso & \\
\hline Música & $\begin{array}{l}\text { Música y Tecnología del } \\
\text { Sonido }\end{array}$ & U. del Pacífico & \\
\hline Música & Interpretación Musical & U. Católica de Chile & \\
\hline Música & Teoría y Literatura Musical & U. Católica de Chile & \\
\hline Música & $\begin{array}{l}\text { Composición Musical / } \\
\text { Musicología }\end{array}$ & U. Católica de Chile & \\
\hline Música & Dirección Coral & U. Católica de Chile & \\
\hline
\end{tabular}

continúa.. 
142 LA ACREDITACIÓN DE LAS CARRERAS ARTÍSTICAS DE PREGRADO EN CHILE I. Villegas

\begin{tabular}{|c|c|c|c|}
\hline Disciplina & Nombre carrera & Universidad & Acreditada \\
\hline Música & Interpretación Musical & $\begin{array}{l}\text { Universidad de las } \\
\text { Américas }\end{array}$ & \\
\hline Música & Canto & $\begin{array}{l}\text { Universidad de las } \\
\text { Américas }\end{array}$ & \\
\hline Música & Lic. en Música, Teoría & U. de Chile & \\
\hline Música & $\begin{array}{l}\text { Licenciatura en Música, } \\
\text { Interpretación }\end{array}$ & U. de Chile & \\
\hline Música & $\begin{array}{l}\text { Licenciatura en Música, } \\
\text { Sonido }\end{array}$ & U. de Chile & \\
\hline Música & $\begin{array}{l}\text { Licenciatura en Música, } \\
\text { Composición }\end{array}$ & U. de Chile & \\
\hline Música & Licenciatura en Música & $\begin{array}{l}\text { U. Academia de } \\
\text { Humanismo Cristiano }\end{array}$ & \\
\hline Música & Licenciatura Música & U. de La Serena & $\begin{array}{l}2013 \\
\text { Agencia Acreditadora de } \\
\text { Chile }\end{array}$ \\
\hline Música & $\begin{array}{l}\text { Licenciatura en Ciencias } \\
\text { y Artes Musicales }\end{array}$ & U. Católica de Valparaíso & $\begin{array}{l}2019 \\
\text { Agencia Acreditadora de } \\
\text { Chile }\end{array}$ \\
\hline Música & $\begin{array}{l}\text { Licenciatura en } \\
\text { Interpretación Musical }\end{array}$ & U. Católica de Valparaíso & $\begin{array}{l}2017 \\
\text { Agencia Acreditadora de } \\
\text { Chile }\end{array}$ \\
\hline Música & Canto & U. ARCIS & \\
\hline Música & Composición y Arreglos & U. ARCIS & \\
\hline Música & Interpretación & U. ARCIS & \\
\hline Música & Interpretación & U. Austral & \\
\hline Música & Música y Sonido & UNIACC & $\begin{array}{l}\text { Diciembre de } 2015 \\
\text { Agencia A\&C }\end{array}$ \\
\hline
\end{tabular}

Fuentes: Mineduc y Agencias acreditadoras (2012)

(*) No se incluye ninguna acreditación en Pedagogía o plan de formación pedagógica.

\section{Experiencia en el exterior}

Para efectos de observar la realidad chilena en el contexto de otros países latinoamericanos, dedicamos un espacio a estudiar los sistemas de aseguramiento de la calidad universitaria en artes en Argentina, Brasil y México que, por el tamaño, resultan experiencias complejas y revisamos además el caso de Perú y Ecuador.

No obstante debemos señalar que desde 2003 existe la Red Iberoamericana de Acreditación para la Educación Superior (RIACES), que agrupa a las instituciones asociadas a la acreditación de la calidad 
de la educación superior. RIACES promueve el intercambio de información y experiencias en materia de acreditación y evaluación de la calidad de la educación superior en América Latina y España. Su rol es más bien de observación y vigilancia, cuando no de coordinación de acciones para los países afiliados. Esta asociación apunta además a considerar las complejidades del sistema, la idiosincrasia de cada país y la antigüedad en las respectivas experiencias. Dicho esto pasamos a revisar los casos más relevantes.

\section{a. Argentina}

En el caso de Argentina podemos decir que en términos cuantitativos la acreditación universitaria es baja si tomamos el tamaño del total de la muestra: de 47 universidades estatales (nacionales) y 46 privadas solamente tres de las primeras y cuatro de las segundas estaban acreditadas hacia fines de 2011 y ninguna por más de tres años.

La Comisión Nacional de Evaluación y Acreditación Universitaria -órgano oficial del sistema- emite un listado de carreras de grado y otra con carreras de posgrado, donde se establecen las carreras que, según la Ordenanza 057 CONEAU, son consideradas de interés público y que, por lo tanto, deben acreditarse ${ }^{9}$.

Hay que señalar que en el listado de carreras y posgrados no figuran aquellas del mundo de las artes visuales, música o teatro, por lo tanto su acreditación es voluntaria. Existen tres categorías, A, B y C, para carreras en pleno funcionamiento, las que equivalen a excelente, muy buena, buena. Luego tres categorías para carreras que aún no tienen el dictado completo, es decir, que todavía no cuentan con egresados. Si la institución universitaria lo solicita se categorizan con "an", "cn", "bn", claves equivalentes a excelente, muy buena, buena. Finalmente, existe un mecanismo para acreditar carreras nuevas para las cuales no se extiende la categoría.

\footnotetext{
9 Para mayor información se sugiere visitar el siguiente enlace: http://www.coneau.gov. ar/CONEAU/index.php?option=com_content\&view=article\&id=45:joomla-communityportal\&catid=1:latest-news
} 
144 LA ACREDITACIÓN DE LAS CARRERAS ARTÍSTICAS DE PREGRADO EN CHILE I. Villegas

\section{b. México}

El modelo mexicano es digno de ser considerado. El Consejo para la Acreditación de la Educación Superior de las Artes (CAESA) es una asociación civil reconocida por COPAES (Consejo para la Acreditación de la Educación Superior) y alberga a instituciones estatales y particulares. El organismo ha establecido una serie de protocolos y pautas que, al respetarse, dan validez a la vida académica de carreras universitarias (licenciaturas y carreras técnicas). Es el equivalente a nuestras agencias acreditadoras, solo que especializada en artes. Hay en México -cabe señalar aquí- otras instancias acreditadoras diferentes para ciencias, humanidades, ingenierías y otras disciplinas. COPAES investiga, informa, vigila, supervisa y administra las acreditaciones que entregan las agencias como CAESA y el organismo está administrado por un conjunto de representantes de universidades mexicanas, lo que otorga representatividad y, por lo mismo, equidad al sistema.

Al contrario de otros países, este mecanismo especializado en artes ha permitido una alta competitividad de los programas y un gran número de ellos se encuentra acreditado ${ }^{10}$. CAESA es, pues, un instrumento de las universidades del mundo de las artes, supervigilado por el Estado y altamente especializado.

\section{c. Brasil}

El sistema nacional de evaluación de la enseñanza superior está vigente desde el año 2002, pero sus actividades se remontan a 1995. Participan del sistema en forma integrada el Consejo Nacional de Educación (CNE) a través de la Cámara de Educación Superior, el Ministerio de Educación (MEC) a través de la Secretaría de Enseñanza Superior (SESU), el Instituto Nacional de Investigaciones (INEP) y CAPES, encargado de la enseñanza de posgrado en Brasil. La Ley 3860/2001 rige el sistema nacional de enseñanza universitaria, así como su mecanismo de evaluación. El sistema procede de la misma manera ya habitual: una autoevaluación, una evaluación institucional

10 Sugerimos revisar el siguiente enlace para mayor información: http://www.caesa-artes.org/ old/entregaconstancias.html y el listado de programas acreditados en http://www.caesa-artes. org/old/acreditados.html 
de la carrera, una evaluación de los graduados (o de posgraduados, según se trate de carreras de grado o posgrado) y los datos del censo de educación superior.

Las áreas que se evalúan en este proceso no difieren mayormente de los criterios y dimensiones utilizadas en Chile (recursos humanos, reglamentos, infraestructura, finanzas, etc.). No obstante, cada evaluación de un programa es revisada por el mecanismo de acreditación institucional que entrega datos respecto de la universidad que aloja al programa que busca acreditarse.

Sin embargo, el sistema brasileño aplica un examen nacional de cursos (ENC) que mide el aprendizaje para cada programa en los estudiantes de último año. Esta prueba tiene el carácter de obligatorio. Los resultados (que se aplican en todo el país el mismo día y hora) llevan nota A, B, C, D, E (de mayor a menor calidad, donde D y E serían malos resultados). Estos conceptos de aprobación/reprobación dan pie a un ranking nacional de oferta (CO). En 2001, con una validez de cinco años, se confeccionó un listado de carreras rankeadas integrado por cuatro mil cursos de 20 carreras profesionales (278.668 alumnos). Salvo el área de letras, no hay carreras del mundo del arte que en esos años hayan aceptado someterse al sistema. En el proceso del año siguiente (2002) tampoco $^{11}$.

\section{d. Perú}

El Sistema Nacional de Evaluación, Acreditación y Certificación de la Calidad Educativa (SINEACE) del Perú fue creado por Ley No 28.740 de mayo de 2006, se trata de una institucionalidad con algo más de seis años de experiencia.

El SINEACE está constituido por un conjunto de organismos que velan por la calidad de la educación superior: IPEBA, para instituciones de educación básica y técnicas; CONEACES para la educación no universitaria y CONEAU (Consejo de Evaluación, Acreditación y Certificación de la Calidad de la Educación Superior Universitaria)

11 Para mayor información al respecto se puede revisar el siguiente enlace: http://www.cedus. cl/files/acr_br_soares.pdf 
para la educación universitaria. Las tres funciones principales de CONEAU son: definir criterios e indicadores de evaluación para procesos de acreditación y certificación de las instituciones y programas de educación superior universitaria; aprobar normas y fomentar la cultura evaluativa en las instituciones de educación superior universitaria; y publicar y difundir resultados de procesos de evaluación de enseñanza. CONEAU posee un directorio conformado por seis expertos, propuestos por CONCYTEC (Consejo de Ciencia y Tecnología); un representante de las universidades públicas, uno de las privadas; un representante del consejo de decanos de colegios profesionales; y un representante de CEPLAN (Comisión de Planeamiento Estratégico Nacional). La ley del SINEACE rige por igual a todas las disciplinas y no hay distinciones entre áreas disciplinarias, sin embargo, el SINEACE ha emitido estándares de calidad para diversas carreras ${ }^{12}$, aunque no los hay para la enseñanza artística.

El SINEACE es la institución que articula el funcionamiento de los órganos operadores del sistema (agencias acreditadoras), garantiza la independencia de dichos órganos, vela por el cumplimiento de las leyes, comunica políticas, acciones y resultados. El SINEACE tiene un órgano rector que es el consejo superior dirigido por un presidente. Cada órgano operador posee listados actualizados de cada una de sus agencias de acreditación (entidades especializadas de evaluación).

Tal vez por ser un sistema relativamente nuevo, CONEAU solamente ha logrado acreditar cinco carreras de universidades distintas. A cuatro de ellas les ha otorgado la acreditación y a una de ellas le ha reconocido la acreditación otorgada por una entidad extranjera (CNA de Colombia). De las 134 universidades reconocidas formalmente en Perú solo una de ellas -de carácter particular- (Universidad Cayetano Heredia de Lima) está acreditada por CONEAU $^{13}$; se espera que para 2013, siete universidades más alcancen la acreditación.

12 A partir de 2009 se han establecido parámetros, estándares y modelos de calidad para programas de pregrado: Medicina, Obstetricia, Enfermería, Nutrición, Psicología, Ciencias biológicas, Odontología y Trabajo social. También para doctorados y maestrías.

13 Para mayores informaciones se puede visitar el siguiente enlace: http://www.unsa.edu.pe/ ofrrpp/entrevistas/solamente-hay-una-universidad-acreditada-por-el-coneau-en-el-peru/ 
La acreditación se otorga por cinco años y es renovable. El mecanismo es el tradicional empleado en Chile y en otros países, donde operan criterios evaluativos declarados, sistemas de autoevaluación, pares evaluadores, informes de pares, respuesta al informe de pares y finalmente actas de acreditación donde se expresan los resultados y metas que debe lograr el programa (plan de mejoras).

\section{e. Ecuador}

El organismo acreditador ecuatoriano es el Consejo de Evaluación, Acreditación y Aseguramiento de la Calidad de la Educación Superior (CEEACES).

Este contribuye al aseguramiento de la calidad de las instituciones, programas y carreras que integran el sistema nacional de educación superior. Aplica procesos de evaluación y autoevaluación para visibilizar la rendición social de cuentas de los centros de educación superior. El sistema nacional y, evidentemente el CEEACES, se rige por la ley del 12 de octubre de 2010. El CEEACES es dirigido por un equipo de seis académicos.

Hay un hecho que marca de modo radical un cambio en los procedimientos que aseguran la calidad de la educación superior en Ecuador: el Mandato No 14. En Ecuador, el año 2012 marcó el inicio de un movimiento fuerte en materia de aseguramiento de la calidad; catorce universidades -solo en la categoría E- fueron cerradas por el Consejo de Educación Superior, a causa de no superar los estándares para continuar funcionando, todo esto en el marco del Mandato $\mathrm{N}^{\circ} 14$.

Este deroga la Ley $\mathrm{N}^{\circ} 130$ que permitía la creación de una universidad y a propósito del cual se dejaron ver claramente irregularidades y defectos jurídicos que, según la Asamblea Constituyente, empañaban el normal y transparente ejercicio de la ley en materia de educación superior. Dicho mandato, en su artículo transitorio No 1 obliga a CONESUP (Consejo de Educación Superior) a que "determine en el plazo de un año la situación académica y jurídica de todas las entidades educativas bajo su control en base al cumplimiento de sus disposiciones y de las normas que, sobre 
educación superior, se encuentran vigentes en el país"14 (Asamblea Constituyente del Ecuador, 2007).

La idea de fondo del Mandato $N^{\circ} 14$ fue depurar el sistema y mejorar la calidad de la enseñanza universitaria en el plazo de un año a partir de julio de 2009. En abril de 2010, una subcomisión legislativa descalificó los estudios realizados por CONESUP y CONEA que habían clasificado a las universidades con la escala A, B, C, D y E. Dicha subcomisión consideró que las calificaciones dadas a las universidades no eran vinculantes para permitir su cierre en caso de mala calidad, debido a que el estudio efectuado en el amparo del Mandato $N^{\circ} 14$ no fue acucioso y estaba lleno de irregularidades tanto metodológicas como jurídicas. Se acusó a CONEA y CONESUP de no haber cumplido con su encargo. No obstante, a la luz del informe, las instituciones con letra E debían cerrar; había 26 de ellas en esa situación.

En el 2012 en Ecuador se cerraron más de 30 universidades de diversas categorías y el proceso de análisis de la calidad de las instituciones universitarias (universidades, carreras de pre y posgrado) sigue su marcha hasta el día de hoy. Las que no cumplan con un estándar básico deberán cerrar hacia el año 2014.

Hasta el momento las universidades evaluadas por CONEA con letra A son solo 11 de 71, entre ellas: la Facultad Latinoamericana de Ciencias Sociales (FLACSO), la Universidad Católica de Quito, Técnica de Loja, Espoch de Riobamba y ESPE de Quito, la idea es procurar solo la existencia de un total de 26 universidades de categoría A. Los programas académicos en tanto, sean de pregrado o posgrado, deben cumplir con una serie de normas, no muy distintas de las que habitualmente se exigen en los sistemas de aseguramiento de la calidad de la enseñanza universitaria, a saber: calidad y grados universitarios de los profesores, tasa de graduación y retención de sus estudiantes, tipo de contrato de sus académicos, productividad de los académicos, calidad de la infraestructura, calidad de los egresados y su empleabilidad, etc.

14 En la web: http://www.uce.edu.ec/documents/22994/731102/BASE\%20LEGAL\%20 mandato\%2014.pdf 
En el plan estatal para la revisión de la calidad de las universidades y programas se incluyen por igual carreras de ciencias y de artes.

\section{CNCA de Chile y la acreditación en artes}

Entre abril y agosto de 2011, el Consejo Nacional de la Cultura y las Artes de Chile, CNCA, preparó un informe denominado Construcción de la propuesta de criterios específicos de acreditación para carreras artísticas de pregrado, documento con el cual esperaban cerrar su participación en el tema de educación artística, toda vez que el Estado retiró de las políticas del CNCA los temas relativos a esta. La construcción de la propuesta se basó en el trabajo realizado entre 2007 y 2010 por las denominadas "mesas técnicas" y fue sistematizada con la participación de directivos, docentes y profesionales del área de artes.

El documento da cuenta de los resultados de la labor y fue ejecutado mediante dos mesas de trabajo, la primera a cargo de redactar los resultados y la segunda responsable de ratificar dichos productos. Se dieron a conocer de esa forma los indicadores específicos para la acreditación de carreras artísticas de pregrado. Esta última etapa de trabajo tenía objetivos específicos.

- Diseñar una metodología para implementar el proceso de validación de los indicadores específicos para la acreditación de carreras artísticas de pregrado.

- Elaborar una propuesta de indicadores específicos para la acreditación de carreras artísticas de pregrado, validadas en mesas de trabajo con directivos y académicos de carreras artísticas de las principales universidades chilenas.

- Elaborar un informe final que dé cuenta de la estrategia llevada a cabo, la sistematización de la información y las conclusiones acerca de los indicadores específicos de acreditación para carreras artísticas de pregrado, para ser presentado a la CNA.

Hay tres aspectos metodológicos que llaman la atención:

a. Que los participantes de las mesas técnicas no poseen igual jerarquía ni vinculación al interior de sus respectivos programas o 
carreras. De esta forma, mientras algunos son solo docentes, otros son decanos, o bien, pertenecen a la oficina de acreditación de la universidad que representan. No miran, entonces, el problema desde la misma perspectiva.

b. No hay representantes de programas artísticos de pregrado de universidades de provincia, lo cual otorga un sesgo al estudio. Aunque un programa de formación artística no debiera ser de distinta calidad por dictarse en provincia, sí es factible (o esperable) encontrar cualidades específicas de un programa producto de su ubicación geográfica.

c. Hay universidades con mayor representación que otras. Compuestas por 14 personas, en estas mesas se representan 12 universidades: uno de estos representantes es de la Pontificia Universidad Católica, dos de la Universidad de Chile, tres de la UNIACC, dos de la Universidad Finis Terrae, uno de la Universidad Diego Portales, uno de la Universidad del Desarrollo y dos de la Universidad Católica Silva Henríquez. Esto podría generar una visión alterada de las formas de hacer docencia en universidades que tienen mucha o poca trayectoria (experiencia), considerándose dichas prácticas como corrientes, cuando tal vez son excepcionales. En las universidades participantes solo dos universidades están en la categoría de "tradicional" y solo una de ellas corresponde a una universidad estatal. El documento no hace mención a este hecho.

De la misma forma las disciplinas no están representadas en igual número de personas. Mientras teatro, artes visuales y audiovisual cuentan con dos personas, música y danza están representadas por una sola, respectivamente.

La propuesta de indicadores específicos que resultó de esta labor es en la práctica una serie de solicitudes y obligaciones impuestas a las carreras y no ofrece rasgos específicos para carreras del mundo de las artes. En el Anexo 1 se enuncia un resumen de los indicadores, en versalita los casos en los que se ha considerado un rasgo particular dado por las artes.

Consideramos valioso el aporte de las mesas en cuanto a una propuesta puntual para mejorar el mecanismo de aseguramiento 
de la calidad en carreras universitarias y particularmente del área artística. El CNCA realizó el único intento que se ha hecho hasta el momento de generar una diferencia entre una acreditación generalista indiferenciada disciplinariamente y un proceso centrado en las artes, con características precisas.

\section{Conclusión}

Los programas de artes aún no se incorporan plenamente a los procesos de acreditación en Chile, observándose que hacia diciembre de 2012, solo el 19\% de los programas universitarios chilenos en esta área se encuentran acreditados. Para revertir esta situación, avanzando hacia una plena acreditación de ellos, debería incorporarse a los equipos directivos de las unidades académicas del área artística, personal académico experto en evaluación cualitativa y cuantitativa.

Por su parte, el sistema nacional de aseguramiento de la calidad provee solo cuatro agencias que abordan el mundo de las artes. En conjunto suman 274 evaluadores, 83\% de los cuales es de Santiago y cerca de un tercio de ellos $(3,4 \%)$ proviene de dos universidades chilenas. La participación de evaluadores académicos, artistas y teóricos formados y con empleo actual en todas las universidades del país, estatales o privadas (sean o no tradicionales) es una necesidad vital para ampliar la visión, los modelos culturales y los criterios de análisis de las evaluaciones, aportando otros epistemes al proceso. Junto con una mayor participación de instituciones de provincia es necesario que las agencias incorporen pares evaluadores expertos y adiestrados en evaluación cualitativa y cuantitativa, toda vez que el número de doctores, que podríamos considerar como realmente preparados para esa función, solo ocupan una mínima parte del plantel de docentes universitarios chilenos y no participan en número importante como evaluadores de las agencias de acreditación.

El sistema nacional de aseguramiento de la calidad de la enseñanza universitaria debiera prepararse para el ingreso de las carreras artísticas a los procesos de acreditación, para lo cual será necesario atender las consideraciones epistemológicas que el pensamiento contemporáneo posee respecto del arte y la cultura, 
respetando la diversidad de visiones que estos programas tengan, aunque se contradigan con los postulados de las universidades que los acogen o sean contrapuestos a las ideas del propio par evaluador. En relación con las actas de acuerdo debemos señalar que la revisión de estos documentos nos hace ver que en su aspecto formal a todos los programas se les mide lo mismo: fortalezas y debilidades para cada una de las dimensiones de evaluación, a saber perfil de egreso y resultados; condiciones de operación; y capacidad de autorregulación.

No obstante los puntos que se tocan en un programa u otro varían en tamaño e importancia, incluso dentro de una misma agencia: veamos el caso de la Agencia Acreditadora de Chile, en su acuerdo No 73 (UNIACC, Artes Visuales) entrega 10 observaciones para perfil de egreso y resultados y solo uno de esos puntos es negativo; para la carrera de Ciencias Musicales (acuerdo $\mathrm{N}^{\circ}$ 104) se entregan nueve observaciones para perfil de egreso y resultados, solo uno de los aspectos es negativo y se ofrece como recomendación. Esta última fue acreditada por siete años, en tanto la primera que mencionamos por cuatro.

Si revisamos el acta de acuerdo de la agencia AAD S.A. para la carrera de Arte de la Universidad Católica, el acuerdo de acreditación No 14 tiene otro formato. El "téngase presente" suma siete aspectos y los "considerandos" mezclan aspectos de las tres dimensiones que ya detallábamos en las otras agencias. Se mezclan también las fortalezas (4) con las debilidades (6). Otorgó cinco años a dicho programa. En otras palabras, los formatos no son los mismos y los aspectos que se abordan dentro de una misma área tampoco son iguales en el caso de distintos programas. Entendemos que muchas veces la disciplina puede generar una diferencia, pero lo que no se termina por comprender es que los aspectos que se observan en un programa no estén considerados en otro.

En todos los casos las observaciones que se hacen son casi iguales y más bien de sentido común. Se repiten frases como: "el plan de estudio está claramente definido", "la actualización del plan de estudio está bien definida", "el perfil de egreso es claro", "el plan de estudio es coherente con los lineamientos generales”, etc. 
No hay tampoco ninguna observación referida a las líneas de trabajo en torno a la creación artística, es decir, a la parte proyectual de las carreras centradas en el arte y la creación artística.

En este sentido, por ejemplo, Qualitas pide a la Universidad Finis Terrae en su acta final de acreditación que mejore el perfeccionamiento docente, asunto que ADD. S.A. no pide a la Escuela de Arte de la Universidad Católica. La agencia AAD S.A. indica a esa escuela de arte que debe "consensuar, internalizar y mejorar la difusión de los reglamentos internos, fundamentalmente aquellos que atañen al estudiantado". Sin embargo, la Escuela de Arte de la Universidad Finis Terrae ni siquiera publica dichos reglamentos y la agencia acreditadora no se lo señala como una falta. En otras palabras, lo que es necesario y constituye una falta para un programa, no es necesario ni constituye una falta para otro. No existe un ente que vigile esta discrepancia de criterios.

Finalmente y siendo prácticos:

1. Los programas debieran declarar el tipo de vinculación/ permanencia del académico con el programa. En razón de ello un programa no debería presentarse a un proceso de acreditación si no cuenta con una planta que exhiba sus sistemas de adscripción y sus niveles de graduación y posgraduación. Lo primero significa expresar el rango académico de sus profesores (instructores, adjuntos, asociados o titulares empleando la nomenclatura usada en su institución), lo segundo implica saber su nivel de estudios y la institución que otorgó sus grados. Esto último expone de manera precisa la filiación de sus docentes con sus respectivas casas de estudio y la ideología o ideas basales de un docente respecto de su disciplina.

2. Todo programa acreditado debería publicar en Internet el acta de acreditación de la agencia acreditadora, de modo de reflejar de manera directa las fortalezas y debilidades de la oferta académica.

3. Toda acta de acreditación - sin importar la agencia que lo emitedebiera contener los mismos aspectos observados en cualquier caso, de manera que lo que se le solicita a un programa sea lo mismo que se le solicita a otro. Esto facilita al usuario la comparación entre dos o más programas acreditados. 
4. El currículum vitae de los profesores universitarios de arte debería ser una matriz igual para todas las escuelas artísticas chilenas, de manera que el usuario pueda comparar niveles entre las distintas carreras artísticas. Dicho currículum debiera ser de conocimiento público y contener, por lo menos los siguientes datos: último grado académico cursado y fecha; productividad en docencia (número de cursos y estudiantes a los que va dirigido), productividad en investigación o creación (proyectos realizados, publicaciones, obras abiertas al público, pasantías, patentes), de los últimos cinco años.

5. Un alto porcentaje de pares evaluadores de una agencia acreditadora deberían ser posgraduados, master, magíster y/o doctorados, haciendo público el nombre de la universidad que otorgó dicho posgrado. Esto asegura, por lo menos, el dominio de algunas herramientas asociadas a la metodología investigativa, lo cual a su vez certifica la idoneidad respecto de materias asociadas con evaluación y métrica, más aún en el área artística donde esos profesionales son menos numerosos.

6. Todas las agencias acreditadoras deberían tener listados públicos de sus pares evaluadores con sus respectivos currículum vitae. Es decir, no es suficiente el nombre del evaluador, sino que lo verdaderamente interesante y valioso es el récord de acciones y actividades centradas en la disciplina artística que se examina.

7. El porcentaje necesario de profesores/hora, jornadas completas y medias, y su respectivo nivel de estudios, debería estar reglamentado para un programa de pregrado. Esto entregaría a un programa universitario la verificación de un piso mínimo de competencias disciplinarias.

8. El nombre del responsable del proceso de acreditación de un programa universitario debiera ser de público conocimiento, ya que ello implica que hay un responsable visible.

9. Chile, al igual que México desde hace años, debiera contar con una oficina especializada en acreditación para programas de artes. Esta iniciativa genera una descarga del sistema nacional, trasladando las especificidades del mundo del arte a instituciones especializadas.

10. Todo currículum vitae de un académico, ya sea profesor o par 
evaluador, debiera contener el nivel de estudios actual y el (o las) área(s) de especialización. Hay algunos que se ven completos, pero no están actualizados.

11. La Ley $\mathrm{N}^{\circ} 20.129$ no establece pautas ni fija normas en cuanto al número de pares de evaluadores registrados, así como tampoco solicita un nivel de especialización concreta para estos evaluadores, salvo el que deben "ser reconocidos en su área de especialidad". Esto ha generado que los listados de pares evaluadores de las cuatro agencias sean dispares en número: 16 pares en una agencia y 141 en otra.

12. Capital humano: para evaluar un programa de arte en Chile, las agencias exhiben un listado de evaluadores que trabajan principalmente en la Universidad de Chile $(17,2 \%)$ y se han formado en esta misma casa de estudios (76,28\%), así como en la Universidad Católica (27 de ellos, lo que equivalente al 10\%) y en el extranjero como último grado adquirido (91, equivalente al 33\%); observamos entonces que un tercio (38\%) de los pares evaluadores proviene de solo dos universidades (tradicionales) chilenas y que el $83 \%$ es de Santiago, con lo cual queda en evidencia el disminuido número de pares evaluadores de otras regiones del país. Claramente se trata de una debilidad del sistema que puede generar dudas respecto del esfuerzo del comité de pares por "(...) comprender los principales aspectos relativos a la cultura, principios y estilos de la institución visitada, de modo que estos sean los que proporcionen el marco de referencia de la evaluación" (CNA, 2008, p. 13). Un hecho interesante de observar es que existe un alto número de evaluadores (43) que trabaja en Centros de Formación Técnica y no en universidades.

En forma natural y debido a lo nuevo del sistema, no hay formación previa en evaluaciones de procesos de acreditación en nuestro país. La ley no obligó a las agencias a la preparación o formación de sus evaluadores y el Manual de pares evaluadores (2008) de CNA, solo "(...) espera que los pares evaluadores se comprometan a (...) participar en las instancias de entrenamiento o capacitación que sean requeridas" (p. 11). CNA y las agencias han implementado cursos, seminarios y talleres, donde se abordan conocimientos y 
técnicas asociadas a metodologías de evaluación y ética para el rol de par evaluador en procesos de acreditación.

Las agencias acreditadoras no disponen por el momento de una extensa masa crítica cuyo currículum vitae asegure la experiencia en procesos de evaluación complejos, lo que podría estar demostrado con el grado de doctor. El sistema universitario nacional muestra para el área de artes solo un 9\% de académicos de pregrado con el grado de doctor y entre los pares evaluadores solo contamos con 47 doctores, siendo la agencia Aespigar la que posee el mayor número de pares evaluadores doctores (38) y la agencia AAD S.A. la que tiene la menor cantidad de pares evaluadores con grado de doctor (1).

\section{Algunas reflexiones acerca del rol de los pares evaluadores}

En relación con el rol de los evaluadores, hay varios puntos que se destacan en el ejercicio de su labor y que en el área de las artes son de particular relevancia.

- Objetividad: en la revisión de los programas de licenciatura en el área de artes visuales observamos hoy, a lo menos, tres nociones distintas de arte y, por lo mismo, tres epistemes diferentes, aunque si nos basamos en la noción de interdisciplina, ya bastante difundida, las aceptaremos como complementarias. Básicamente estas son: la enseñanza del arte entendida como desarrollo de capacidades centradas en las técnicas tradicionales como procedimiento; otro centrado en la producción de obra como resultado del procedimiento constructivo y de indagación teórica, y un tercero con acento en la práctica de tecnologías de última generación.

Difícilmente encontraremos evaluadores que no estén formados en alguno de estos tres modelos de pensamiento y acción académica. Por lo mismo, lo primero y más relevante es aplicar la máxima objetividad en los procesos de evaluación con prescindencia de si el modelo observado se ajusta o no a las propias ideas, postulados o paradigmas. Solo eliminando el sesgo que puede dar el peso de la posición teórica y epistemológica, 
el evaluador puede verificar datos cualitativos y cuantitativos. Lo que un evaluador supone debería ser una escuela de arte es absolutamente prescindible a la hora de chequear la consistencia de un programa.

- Contrastar los escenarios o contextos: tal como declara House (1997), es preciso evaluar sobre el enfoque de objetivos, donde se consideran las metas del programa y sus frutos, más que los contextos. Sin embargo, y pese a que no lo evaluamos, el contexto fija el marco donde se realiza la labor de enseñanza/ aprendizaje. Un programa con objetivos y declaraciones propias opera al interior de un sistema universitario y de una universidad en particular, es decir, un contexto institucional, con el cual, no obstante, puede tener contradicciones, hecho que bien podría no restar potencia a las acciones, en tanto se cumpla con las declaraciones hechas respecto de los objetivos, desempeño y logros.

Dicho en otras palabras, el proceso comprende dos escenarios, uno que considera a la universidad como un conjunto de principios, misiones, visiones y objetivos y un segundo que considera los objetivos y logros de un programa concreto. Es posible que las declaraciones del primero no coincidan con el segundo, pero de ser así, prevalecerán las declaraciones del programa que se evalúa y no aquellas de la institución a la que pertenece. Hay que considerar que un programa de artes y su evaluación implica de suyo abordar una determinada visión del mundo, del sujeto y de la sociedad, que está siempre correlacionada con una ideología. Un programa de artes implica la práctica de una ideología, propia de la cultura artística, con técnicas, ideas y resultados siempre cambiantes. El arte no es un ente abstracto único e ideal que considera siempre un mismo método y se ubica siempre en una misma posición ideológica respecto de la producción material y el rol del artista. Es posible que estas ideas no estén siempre alineadas consecuentemente y en forma plena con el pensamiento de la universidad sostenedora.

- Valorar la capacidad de identificar fortalezas y debilidades en concordancia con los datos recogidos y el plan de mejoramiento. Metodológicamente no es posible olvidar que se evalúa sobre 
una evaluación ya efectuada, una autoevaluación. El comité de pares no valora en forma directa el programa, sino que lo hace mediante el informe de un proceso (previo) de autoevaluación, donde se detecta y se mide la consistencia y claridad del mismo. Esto significa que la unidad debió aislar, en la medida de lo posible y en forma consistente, coherente y pertinente, las fortalezas y debilidades de todas las dimensiones que considera el proceso y que se refleja en un informe de autoevaluación, sus formularios y anexos.

Los evaluadores de un comité de pares deberían esforzarse por detectar nuevas zonas fuertes y débiles, o bien, analizar si el método de identificación, la conclusión y las acciones de mejoría que propone el programa son correctos y consistentes. Repetir el enunciado de una fortaleza o debilidad, cuando ya ha sido señalada en un informe de autoevaluación, no hace sino debilitar el cumplimiento de la misión del comité de pares, pues desvía su labor generando una segunda evaluación directa. No se trata de que los pares evaluadores deban llegar por obligación a conclusiones distintas de las planteadas por la carrera que se evalúa; se trata simplemente de que los pares evaluadores deben aprovechar su mirada desde el exterior, planteando posiciones críticas, comentarios y observaciones nuevas, aportadoras y complementarias a la mirada del programa que se evalúa.

- Cruce de datos cualitativos y cuantitativos: es preciso diferenciar entre la apreciación de las conductas y contenidos de los entrevistados, de la cuantía expresada en los datos que se tienen a la vista. Los segundos operan sobre los primeros a condición de que las técnicas e instrumentos utilizados hayan sido adecuados y los resultados correctamente interpretados. Dicho de otra manera, un evaluador mide y contrasta la consistencia de la relación directa entre aquello que se indica en el resultado de la autoevaluación (informe de autoevaluación y formularios), con los datos que aportan los entrevistados. Recordemos que se está en presencia aquí del reporte de datos que entregan dos metodologías distintas, una cualitativa y otra cuantitativa. En la primera, la cuantía de la medición es independiente de las fluctuaciones o periodicidades del hecho; en la segunda interesa el registro y el análisis de los 
comportamientos recurrentes y masivos, y la calidad de los atributos que tengan los hechos.

- Verificación y confiabilidad en los datos que aporta la unidad o programa: la validez y la confiabilidad de los instrumentos que aplica una unidad para la obtención del dato que se entrega como recurso a evaluar son dos elementos clave que un evaluador debe verificar, es decir, revisar los cuestionarios y verificar si su aplicación da garantías de confiabilidad. En otras palabras, si el instrumento que se aplica es el correcto para obtener el dato que se busca y luego si el instrumento que se aplica se comporta siempre de manera similar para observar el mismo hecho. Es necesario entonces observar las desviaciones estándar, la recurrencia o permanencia de los datos que entregan las encuestas y/o entrevistas, el cambio de los resultados de un grupo humano a otro. Luego, cuando ocurra, habrá que comprender las razones del cambio y verificar si el universo (n) es suficiente en razón del número total de la población.

En los procesos de reacreditación, lejos aún de ocurrir en nuestro país en la disciplina que aquí examinamos, es relevante tener en consideración el principio de confiabilidad según lo plantea Anastasi y Urbina (1998), es decir, la consistencia de los datos que arrojan las mismas personas al examinárseles en distinto momento (en condiciones distintas) y en conjuntos equivalentes. Esto debido a que los programas deberían entregar datos de cuestionarios y tabulaciones de las mismas poblaciones académicas capturadas en distinto momento, asunto del todo relevante a la hora de una segunda acreditación.

- Entrevistas: idealmente estas se debieran generar en el segundo o tercer día de una visita, ya que buscan básicamente comprobar los valores que arroja un instrumento ya aplicado (encuestas previamente aplicadas por la unidad). Una unidad académica implica un conjunto de personas, que perfectamente podrá tener discrepancias con sus directivos, podrá sentir disconformidad con sus respectivos espacios físicos e infraestructura o malestar entre grupos disciplinarios. Una Licenciatura en Artes Visuales -por ejemplo-implica la labor de académicos artistas, que sabemos que postulan ideas y consecuentemente resultados de distinta índole 
o muchas veces de distinta naturaleza, asunto que constituye un capital y garantiza la diversidad necesaria en el arte. Es esperable entonces encontrar contradicciones. Ponderar las respuestas en una entrevista implica contrastar los datos que se manejan en los formularios de análisis cualitativo y cuantitativo que se levantaron en la autoevaluación, con el sentir de la población. Básicamente las encuestas que entregan los programas que se han autoevaluado son de percepción y miden satisfacción de las personas entrevistadas, coherencia entre lo que hacen y lo que dicen y la efectividad de los procesos.

Satisfacción: se trata del grado en el que las condiciones objetivas y subjetivas de la labor que desempeñan afectan los objetivos que se proponen, tanto los estudiantes, administrativos o profesores.

Coherencia: se trata de que las respuestas que entregan los entrevistados se vinculan o no directamente con aquello para lo cual están orientadas sus labores en el contexto donde trabajan. La suma de los enunciados debiera apuntar a reflejar una misma realidad. De esa forma un profesor podrá manifestar que no cuenta con material suficiente para su labor de experimentación, por ejemplo, con metales, siendo que la unidad no considera entre sus prioridades tal actividad. En este caso es necesario ponderar la respuesta en función de los objetivos del programa, contrastando declaraciones con objetivos.

Efectividad: apunta a detectar si las acciones del entrevistado, las acciones de los otros (pares y aparato administrativo) y las condiciones permiten o no el cumplimiento de las metas que se han propuesto, es decir, puede estar poco satisfecho; sin embargo, su labor puede ser efectiva y cumplir los objetivos plenamente.

- Datos segmentados y generalización: suponer que la realidad de una unidad es de determinada manera a partir del conocimiento (ya sea oficioso u oficial) y/o el análisis de solo un segmento de la información total puede representar el riesgo de asumir como cierta una generalización teórica equívoca.

La comunidad de artistas-teóricos docentes de artes en Chile es pequeña, en general conforman un grupo humano conocido y reconocido por ellos mismos. Será normal, entonces, que 
un evaluador chileno conozca a una buena parte del claustro académico que visita y tenga visiones muchas veces parciales (cuando no dislocadas) y segmentadas del programa que evalúa. Dos acciones deberían ponerse en marcha aquí a raíz de este rasgo. La información previa y oficiosa -muchas veces extrauniversitariarespecto del programa que evalúa deberá particularmente dejarse de lado, incluso expresando el riesgo en forma verbal ante su comité de pares. La información que posee (previa y oficiosa) no deberá prestarse para generalizar acerca del conjunto de dimensiones que abarca la evaluación, incluso menos cuando esta puede afectar el juicio -negativo o positivo- que muchas veces se emite en un informe final.

\section{Referencias}

Alonso L., E. (1999). Sujeto y discurso, lugar de la entrevista abierta en las prácticas de la sociología cualitativa. En: Delgado, J. y Gutiérrez, J. (Coords.). Métodos y técnicas cualitativas de investigación en ciencias sociales, pp. 225-240. Madrid: Síntesis.

Anastasi, A. y Urbina, S. (1998). Test psicológicos. Ciudad de México: Prentice Hall.

Comisión Nacional de Acreditación. (2008). Manual de pares evaluadores. Santiago de Chile: Comité ejecutivo.

Delgado, J. y Gutiérrez, J. (1994). Métodos y técnicas cualitativas de investigación en ciencias sociales. Madrid: Síntesis.

House, E. (1997). Evaluación ética y poder. Madrid: Morata.

Ley N 20.129 "Establece un Sistema Nacional de Aseguramiento de la Calidad de la Educación Superior". Diario Oficial de la República de Chile, Santiago, Chile, 17 de noviembre de 2006.

Sejías, A. (2002). Evaluación de la calidad en centros educativos. La Coruña: Netbiblo.

Stake, R. (2006). Evaluación comprensiva y evaluación basada en estándares. Barcelona: Graó.

Recibido: 5/12/2013

Aceptado: 5/06/2014 
162 LA ACREDITACIÓN DE LAS CARRERAS ARTÍSTICAS DE PREGRADO EN CHILE I. Villegas

\section{Anexo 1}

INDICADORES ESPECÍFICOS PARA LA ACREDITACIÓN DE CARRERAS ARTÍSTICAS DE PREGRADO

Propuesta de las mesas técnicas del CNCA

\section{A. PERFIL DE EGRESO}

\section{Criterio: Formulación del perfil de egreso}

Indicadores:

a. Formulación explícita, clara y a la vez diferenciada, cuando la carrera ofrezca además de grado, título profesional.

b. Coherencia entre perfil de egreso, plan de estudios y estrategias pedagógicas.

c. El perfil de egreso debiera ser un referente claro para permitir evaluar resultados y progresión de estudiantes.

d. Su definición debe ser la expresión del conocimiento en el medio disciplinario específico.

e. Su formulación debe estar sustentada en evidencias y respaldada por la comunidad académica.

\section{Criterio: Estructura curricular}

Indicadores:

a. La carrera debe estructurar su currículo sobre la base de su perfil de egreso, previamente elaborado; debe considerar las competencias comprometidas. De la misma forma las asignaturas deben responder a los requerimientos del perfil.

b. Deben existir mecanismos adecuados para evaluar la progresión de los estudiantes y el logro de conocimientos, habilidades y actitudes previstas en el perfil de egreso.

c. El plan de estudio y los programas deben ser coherentes y coordinados, difundidos públicamente y consistentes con la declaración de principios y objetivos de la unidad que dicta la carrera. 
d. El Plan de estudio debe CONSIDERAR ACTIVIDADES PRÁCtiCAS y teÓRICAS.

e. Para graduarse/titularse los estudiantes deben desarrollar tesis o proyectos profesionales, acompañados de documentos evaluables o práctica supervisada.

f. La unidad debe contar con mecanismos que permitan evaluar periódicamente los programas y actualizarlos. Esta evaluación debiera considerar a académicos, estudiantes activos, titulados, personajes (con experiencia) externos de la disciplina.

g. El plan de estudio de una CARrera artística debiera CONSIDERAR APRENDIZAJES COMO COMUNICACIÓN (LENGUAJE ORAL Y ESCRITO), PENSAMIENTO CRÍTICO, SOLUCIÓN DE PROBLEMAS, INTERACCIÓN SOCIAL, INICIATIVA PERSONAL O AUTOAPRENDIZAJE, ÉTICA, PENSAMIENTO GLOBALIZADO, FORMACIÓN CIUDADANA, DISCERNIMIENTO ESTÉTICO, CONCIENCIA AMBIENTAL.

h. Garantizar que el proceso de formación se debe realizar en un escenario intelectual y académico.

\section{Criterio: Resultados del proceso de formación}

Indicadores:

a. Las unidades deben seguir a sus estudiantes y graduados para vigilar las tasas de retención, titulación, deserción, niveles de empleabilidad, ingresos, etc.

b. Las unidades deben contar con vínculos con los centros de empleo de sus graduados de manera de poder acceder a información sobre remuneraciones, calidad del desempeño de sus egresados, etc.

c. Cuando sea el caso, las unidades debieran tener esa información a la vista para actualizar currículo.

\section{Criterio: Vinculación con el medio}

Indicadores:

a. La unidad debiera mantener vínculos con el ámbito disciplinario y profesional que le corresponde. De la misma forma, debiera considerar la información que recabe en este ámbito, como un insumo para sus actividades académicas.

b. LA UNIDAD DEBE CONSIDERAR ACCIONES QUE PROMUEVAN LA ACTUALIZACIÓN PROFESIONAL Y DISCIPLINARIA DE SUS ACADÉMICOS. LA PRODUCCIÓN ARTÍSTICA SE CONSIDERA COMO MODELO PARA ELLO. 
c. La unidad debe contar con una política que oriente las actividades de investigación/creación de sus académicos. Debiera definir áreas prioritarias, dotación de recursos humanos y financieros.

d. La unidad debiera saber vincularse con instituciones propias de su medio disciplinario (sector cultural y profesional).

e. Debe saber llevar a cabo actividades de extensión que pongan a disposición de la comunidad sus resultados (a aquel sector denominado área de influencia).

f. Las actividades de servicio cultural deben enmarcarse en una política clara y explícita, que no interfiera con las tareas prioritarias de la carrera.

\section{B. CONDICIONES DE OPERACIÓN}

\section{Criterios de evaluación: Estructura organizacional}

Indicadores:

a. Demostrar que posee un adecuado gobierno y eficaz gestión.

b. Tanto la unidad como la universidad deben tener una estructura organizacional que facilite el logro de su misión y objetivos. De la misma forma deben tener un cuerpo directivo superior con responsabilidades, funciones y atribuciones definidas.

c. Los académicos deben tender al mejoramiento de la calidad del servicio formativo por medio de una evaluación permanente.

d. Los académicos que desempeñan funciones directivas deben contar con calificaciones y experiencia necesarias.

e. Los procesos de evaluación de sus docentes deben basarse en instrumentos que permitan progresar y fortalecer su capacidad de autorregulación.

f. La unidad debe contar con medios y mecanismos que permitan al cuerpo académico participar de la formulación de planes y programas, en la identificación de recursos educacionales requeridos y en el desarrollo de recursos humanos.

g. Deben existir mecanismos de comunicación e información.

h. Debe contar con recursos financieros adecuados.

i. La institución donde se inserta debe garantizar estabilidad y viabilidad financiera a la carrera. De la misma forma, debe 
contemplar una planificación adecuada y mecanismos de control presupuestario.

\section{Criterio de evaluación: Recursos humanos}

Indicadores:

a. La unidad debe demostrar que cuenta con un adecuado número de docentes.

b. De la misma forma, la unidad debe tener criterios claros y conocidos para la contratación y perfeccionamiento de su personal. Asimismo debe tener normas, políticas y mecanismos de incorporación, evaluación, promoción de académicos de acuerdo con los objetivos que declara y su misión.

c. LA IDONEIDAD DE SU CUERPO DOCENTE DEBE BASARSE EN LA RELACIÓN ENTRE LA FORMACIÓN RECIBIDA, EXPERIENCIA, TRAYECTORIA, PRODUCCIÓN (ARTÍSTICA).

d. Debe existir un mecanismo para el perfeccionamiento de sus docentes en el ámbito disciplinario y pedagógico.

e. La unidad debe incentivar y apoyar a sus académicos a participar en actividades de docencia, investigación y creación.

f. Debe existir un mecanismo de evaluación de los docentes que contemple la opinión de sus estudiantes.

g. Debe existir un número suficiente de personal técnico y de apoyo capacitado, en número y dedicación horaria.

Criterios de evaluación: Efectividad del proceso de enseñanza aprendizaje

Indicadores:

a. La unidad debe tener identificados sus criterios y mecanismos de admisión, los cuales deben ser de público conocimiento y, obviamente, los apropiados para que los estudiantes alcancen el grado/título en tiempos razonables.

b. El proceso de enseñanza debe tomar en cuenta las competencias de los estudiantes, la flexibilidad del plan y sus requerimientos. 
Criterio de evaluación: Infraestructura y recursos de aprendizaje

Indicadores:

a. Instalaciones y recursos que permitan cubrir las necesidades y propósitos (resultados), todo lo cual debe ser apropiado en número y calidad.

b. La unidad debe demostrar que el proceso de enseñanza considera el uso adecuado y frecuente de los recursos.

c. Existencia de mecanismos claros para identificar y resolver necesidades y renovación de recursos.

d. Biblioteca accesible, con dotación suficiente de libros, material actualizado, concordante con los planes que declara la unidad/ carrera, con personal especializado, equipos, procesos técnicos, redes.

e. La unidad debe tener infraestructura e instalaciones adecuadas, proporcionales a su tamaño y sus actividades, accesibles y seguras.

f. La unidad debe tener talleres, laboratorios, SAlas, espacios, etc., ADECUADOS PARA LA FORMACIÓN DE ARTISTAS, DANDO SEGURIDAD DE QUE DICHAS INSTALACIONES FACILITAN EL LOGRO DE LOS OBJETIVOS DE LA CARRERA.

g. De la misma forma debe contar con recursos computacionales suficientes en calidad, cantidad y actualización.

h. La unidad debe tener recursos de apoyo al aprendizaje que sean concordantes con el nivel de desarrollo tecnológico propio de la carrera/disciplina.

i. La unidad debe cautelar que sus recintos e instalaciones sean accesibles a académicos, estudiantes y administrativos minusválidos.

j. Los docentes deben mantener actualizado el material didáctico que facilita el aprendizaje.

k. Los docentes deben estimular el desarrollo de la capacidad de aprendizaje autónomo en sus alumnos.

1. La unidad debe dar facilidades para que los estudiantes realicen prácticas profesionales y actividades de titulación/graduación propias del plan de estudio.

m. La unidad debe contar con mecanismos eficaces para identificar 
las necesidades de reposición y actualización de instalaciones, equipos, recursos para la enseñanza.

n. La institución debe contar con instrumentos legales que respalden el uso o propiedad de la infraestructura e instalaciones que sirven a la unidad, asegurando disponibilidad de tiempo y acceso, acorde con las necesidades del plan de estudio.

o. La unidad o institución debe contar con reglamentos claros acerca de los derechos de obras que pertenezcan a terceros, así como de las producidas por estudiantes y profesores.

p. La unidad o institución debe contar con un protocolo para el caso de accidentes de alumnos/profesores (atención de urgencia, seguros).

q. La unidad o institución debiera contar con un servicio de asesoría tanto para asuntos socioeconómicos como de salud.

\section{CAPACIDAD DE AUTORREGULACIÓN}

\section{Criterio de evaluación: Propósitos}

Indicadores:

a. Declaración explícita de los propósitos y misión de la unidad, concordantes con aquellas declaraciones de la institución.

b. Declaración de metas y objetivos acordes con el perfil de egreso y grado académico que desea entregar.

c. Existencia de mecanismos que permitan evaluar el cumplimiento del logro, propósitos.

d. La declaración de la misión debe incluir aspectos significativos como principios, énfasis, pesos relativos de la docencia, investigación, extensión, responsabilidad social e impacto en el entorno.

e. La misión, propósitos y objetivos de la unidad deben ser coherentes con el proyecto de la institución en la cual se inserta. Estos deben ser conocidos y comprendidos por la comunidad universitaria (profesores, administrativos, estudiantes).

f. La unidad debe demostrar que posee y aplica mecanismos que permiten la evaluación periódica de la misión y objetivos de la carrera, así como su ajuste. 


\section{Criterio de evaluación: Integridad institucional}

Indicadores:

a. La unidad debe demostrar condiciones para avanzar en el cumplimiento de su propósito.

b. La unidad debe proporcionar información clara, realista y completa a los usuarios de sus servicios y miembros.

c. La unidad debe organizar y conducir los procesos de toma de decisiones en virtud de los propósitos y objetivos que se ha dado, avanzando responsablemente en el logro de los mismos.

d. Los programas, recursos y equipamiento de que dispone la carrera deben guardar relación con sus propósitos.

e. La unidad debe cuidar que exista un adecuado equilibrio entre el número de alumnos que ingresan a cada curso y el total de recursos del programa, considerando sus académicos, su infraestructura y su presupuesto.

f. La publicidad de la institución en relación con la unidad y de esta misma y, en general, la información directa o indirectamente entregada al público, debe ser clara y expresar fielmente la realidad de la institución.

g. La unidad debe reunir y generar información completa acerca de los servicios que ofrece y sus principales características.

h. La información que genere acerca de los servicios que ofrece debe ser difundida a los usuarios y a la comunidad en general.

i. La unidad debe proporcionar a los estudiantes los servicios ofrecidos y respetar las condiciones esenciales de enseñanza bajo las cuales estos ingresaron a la carrera.

j. La información relativa a los procesos académicos de los alumnos debe estar registrada adecuadamente y ser accesible para su consulta.

k. La unidad debe contemplar mecanismos adecuados para corregir posibles errores en los registros.

1. El cuerpo directivo superior de la unidad debe adoptar sus decisiones con criterio académico.

m. La unidad debe establecer procedimientos adecuados para resolver conflictos de intereses al momento de adoptar sus decisiones. 
n. La unidad debe contar con un reglamento claro y ampliamente difundido donde se establezcan los derechos y deberes de los estudiantes y se consideren aspectos tales como carga docente, calificaciones, normas relativas a la promoción, plan de estudio y eliminación, procedimientos y disposiciones de homologación y convalidación de estudios previos, comportamiento estudiantil y otros.

o. La unidad debe organizar y conducir los procesos de toma de decisiones de acuerdo con la ley y respectivos reglamentos.

p. La unidad debe perfeccionar permanentemente las reglamentaciones y normativas internas de manera que los procesos de toma de decisiones sean públicamente conocidos y debidamente aplicados.

q. La reglamentación académica y las normas aplicadas a los estudiantes, académicos y personal de apoyo debe permitirles organizarse en función de sus intereses estamentales. 